\title{
Advances in endovascular aneurysm management: coiling and adjunctive devices
}

\author{
Jessica K Campos (D) , ${ }^{1}$ Brian V Lien, ${ }^{1}$ Alice S Wang, ${ }^{2}$ Li-Mei Lin (D) ${ }^{3}$
}

To cite: Campos JK, Lien BV, Wang AS, et al. Advances in endovascular aneurysm management: coiling and adjunctive devices. Stroke \& Vascular Neurology 2020;5: e000303. doi:10.1136/svn2019-000303

Received 18 November 2019 Revised 15 February 2020 Accepted 27 February 2020 Published Online First 15 March 2020

Check for updates

(c) Author(s) (or their employer(s)) 2020. Re-use permitted under CC BY-NC. No commercial re-use. See rights and permissions. Published by BMJ.

${ }^{1}$ Department of Neurological Surgery, University of California Irvine Medical Center, Orange, California, USA

${ }^{2}$ College of Osteopathic Medicine of the Pacific, Western University of Health Sciences, Pomona, California, USA

${ }^{3}$ Carondelet Neurological Institute, St. Joseph's Hospital, Carondelet Health Network, Tucson, AZ, United States

Correspondence to Dr Li-Mei Lin, Carondelet Neurological Institute, St. Joseph's Hospital, Carondelet Health Network, Tucson, AZ, United States;

drlimeilin@gmail.com

\section{ABSTRACT}

Endovascular coil embolisation continues to evolve and remains a valid modality in managing ruptured and unruptured cerebral aneurysms. Technological advances in coil properties, adjunctive devices and interventional techniques continue to improve long-term aneurysm occlusion rates. This review elaborates on the latest advances in next-generation endovascular coils and adjunctive coiling techniques for treating cerebral aneurysms.

\section{INTRODUCTION}

The invention of the Guglielmi detachable coil system in the 1990s sparked the development of modern neurointervention and endovascular neurosurgery. ${ }^{1-3}$ While the early results of coil embolisation were met with undesirable occlusion rates, the neuroendovascular space responded with significant advances in coil properties with coils of various lengths, shapes, pliability, coating, detachment zones and devices to assist coil embolisation. ${ }^{3} 4$ Endovascular coiling remains a feasible and effective treatment option for the treatment of ruptured and unruptured aneurysms, especially as an alternative to surgical clipping in most cases, which is associated with higher morbidity and mortality rates. Devices to augment coil embolisation now include balloon-assist techniques and intracranial stents to increase coil packing and parent artery patency, as well as reduce the risk of coil herniation. ${ }^{5}$ Significant changes in coil properties have also been made to increase the aneurysm occlusion rates. ${ }^{6}$

Wide-neck cerebral aneurysms pose unique technical challenges for endovascular coil embolisation. The most common definition for wide-neck aneurysms is a dome-to-neck ratio of less than $2 \mathrm{~mm}$ or a neck diameter equal to or greater than $4 \mathrm{~mm}$. $^{7}$ Some of the challenges associated with coiling of wideneck aneurysms include the tendency of coils to herniate into the parent vessel, as well as difficulty in determining the neck and parent vessel interface and protecting the vessel branches at the neck of the aneurysm. ${ }^{8}$
Adjunctive devices such as intracranial stents and balloons were developed to augment coil embolisation. Balloon-assisted coil embolisation reduces the risk of coil prolapse into the parent artery and can provide immediate proximal control with balloon inflation in case of intraprocedural aneurysm rupture. Similarly, stent-assisted coiling allows for increased coil packing density, critical for the treatment of wide-necked, large and giant aneurysms, thereby significantly improving obliteration rate and reducing aneurysm recurrence rate. ${ }^{5-11}$

Despite the wide adoption of flow diversion technique for the treatment of unruptured intracranial aneurysms, there still remains a need for coiling techniques, particularly in the ruptured setting when use of dual antiplatelet therapy is limited. ${ }^{3}$ In recent years, novel stents and stent-like devices have been designed to serve as adjunctive treatments for endovascular coiling of wide-neck aneurysms. These include Cascade, Comaneci, pCANvas and eCLIPS. Temporary neck bridging devices for coil embolisation, such as Cascade and Comaneci, have some advantages over other adjunctive devices such as permanent stents. Although the placement of permanent stents during coiling is associated with greater durability, it is also associated with higher risk of thromboembolic complications. In addition, permanent stents require platelet inhibition, increasing the risk of haemorrhagic complications. ${ }^{12}$ The Cascade and Comaneci devices provide support during coiling and do not require patients to undergo antiplatelet therapy as they are not permanently deployed. Moreover, Cascade-assisted and Comaneci-assisted embolisation, unlike balloon-assisted embolisation, do not occlude the parent vessel, thus posing lower risks of ischaemia or thrombus formation. Other novel devices, such as pCANvas and eCLIPS, have flow-modifying properties that decrease blood flow into the aneurysm, an important feature given that high shear stress and flow velocity can increase the risk of aneurysm recanalisation and recurrence. ${ }^{13}$ 
In this review, we describe recent advances for endovascular coil embolisation of intracranial aneurysms including a detail review on available adjunctive devices.

\section{ADVANCES IN BALLOON-ASSISTED COILING}

Balloon remodelling during endovascular coiling involves the temporary inflation of a balloon catheter across the aneurysm neck during the placement of coils. ${ }^{5}{ }^{14}$ The balloon catheter increases coil packing density and is removed towards the end of the procedure. In addition, balloon catheter can also be used during the procedure to temporarily occlude the parent artery in the event of aneurysm rupture during coiling. Originally, balloon remodelling used a single low-compliance balloon and was limited to sidewall aneurysms. More compliant balloons are now available, and those commonly used for balloon-assisted coiling include Hyperform and HyperGlide (single lumen), TransForm (single lumen) and Scepter (dual lumen). ${ }^{51516}$ Some of the safety concerns associated with balloon remodelling is the possibility of blood stasis increasing the risk of thrombus formation and thromboembolic events, as well as platelet aggregation of the parent artery during balloon inflation. Repeated inflations and deflations can potentially lead to intimal injury of the vasculature near the aneurysm targeted for intervention. ${ }^{17}$ However, several important studies have demonstrated that the safety profile of balloon-assisted coil embolisation is comparable with that of conventional coiling through prospective multicentre studies. ${ }^{18-20}$

The Analysis of Treatment by Endovascular Approach of Non-ruptured Aneurysms (ATENA) study involving 547 patients found a similar rate of complications comparing balloon remodelling coiling $(11.7 \%)$ and standard coiling $(10.8 \%)$ for use in unruptured aneurysms. Most of the balloons used were HyperForm and HyperGlide. ${ }^{518}$ In the Clinical and Anatomy Results in the Treatment of Ruptured Intracranial Aneurysms (CLARITY) study, balloon remodelling was performed in 792 patients with ruptured intracranial aneurysms in this multicentre prospective study. The rate of perioperative complications and clinical outcomes demonstrated a similar level of safety between conventional coiling and balloon remodelling coiling for the treatment of ruptured intracranial aneurysms. ${ }^{519}$ It is thought that balloon remodelling may simplify the process of endovascular coiling and reduce the risk of complication by reducing total procedure time. ${ }^{5}$ The results of these large-scale multicentre studies support the safety and efficacy of balloon-assisted endovascular coiling, especially for wide-neck intracranial aneurysms where conventional coiling has limited efficacy.

\section{TransForm occlusion balloon catheter}

The TransForm occlusion balloon catheter (Stryker Neurovascular, Fremont, California, USA) is the latest innovation of balloon microcatheter design. It is a single lumen balloon catheter using 0.014-inch microguidewires with compliant and super compliant versions. ${ }^{17}$ The device has a micromachined hypotube design with multiple slits to allow rapid inflation and deflation of the balloon catheter, increased visibility and reduced procedural times. ${ }^{8}$ In an early clinical experience and retrospective review of 23 ruptured and unruptured aneurysms treated with the TransForm, the authors report complete aneurysm occlusion (Raymond Roy Classification (RRC), RRC I) in $78 \%$ $(18 / 23)$ of aneurysms and residual neck in 22\% (5/23) of aneurysms (RRC II) in post-treatment angiography. No serious complications were observed, and no follow-up data were reported. ${ }^{17}$

In a prospective multicentre trial published in 2018, the authors enrolled 81 patients undergoing TransForm balloon-assisted coil embolisation for treatment of ruptured and unruptured aneurysms. Of the aneurysm characteristics reported, $50 \%(36 / 72)$ were bifurcation aneurysms and $82 \%(59 / 72)$ were located in the anterior circulation. Complete occlusion (RRC I) was observed in $69.4 \%(50 / 72)$ of cases, residual neck (RRC II) in $25 \%(18 / 72)$ and residual aneurysm (RRC III) in 5.6\% $(4 / 72)$. In $4.9 \%(4 / 81)$ of subjects, thrombus formation occurred and led to thromboembolic events in $2.5 \%$ $(2 / 81)$. However, no thromboembolic infarctions or serious complications occurred. ${ }^{8}$

\section{Scepter}

Scepter (Microvention, Irvine, California, USA) is a coaxial dual lumen compliant balloon catheter using 0.014 inch microguidewires. ${ }^{8}$ This device was approved by the FDA in 2012. The Scepter balloon has a compliant version for sidewall aneurysms providing minimal slipping and longitudinal coverage called Scepter-G, and a supercompliant version that conforms to bifurcation aneurysms called the Scepter-XC. ${ }^{16}$ The double lumen design of the Scepter balloons provides a unique advantage of the ability to deploy a low profile stent in the event of coil loop prolapse.

\section{HyperForm and HyperGlide}

The HyperForm and HyperGlide balloon catheters are single lumen compliant balloons using 0.010 inch microguidewires. ${ }^{8}$ The HyperGlide is primarily used for balloon remodelling of wide-neck sidewall aneurysms, especially those located in the internal carotid and vertebral arteries. The HyperGlide is oblong, while the HyperForm is round and more compliant. The HyperForm can conform to complex bifurcation aneurysms and protect branches originating from and adjacent to the aneurysm neck. The more compliant HyperForm is preferred for wide-neck aneurysm as well as small arteries, such as posterior inferior cerebellar artery, posterior cerebral artery and anterior communicating artery. The 0.010-inch microwire requirement limits the easy of use and navigability for the HyperFrom and HyperGlide balloons. ${ }^{16}$ 


\section{Ascent balloon}

The Ascent occlusion balloon catheter (Micrus Endovascular Corp, San Jose, California, USA) uses a 0.014-inch microguidewire and has compliant and supercomplaint versions. The device was approved by the FDA for neurovasculature and peripheral use in 2008. These were an older generation balloon design and are no longer routinely used.

\section{ADVANCES IN STENT-ASSISTED COILING PulseRider}

The PulseRider Aneurysm Neck Reconstruction Device (Pulsar Vascular, Inc, Los Gatos, California, USA) comes in two shapes: $\mathrm{T}$ or $\mathrm{Y}$, both of which are made of nitinol (nickel titanium) with $8 \mathrm{~mm}$ and $10 \mathrm{~mm}$ wide arches. It was first approved for use in the USA by the Food and Drug Administration (FDA) on 19 June 2017. ${ }^{21}$ Prior to approval, the Adjunctive Neurovascular Support of Wide-neck Aneurysm Embolization and Reconstruction (ANSWER) Trial examined its use in the treatment of 34 aneurysms. Of the 34 treated aneurysms, $82.4 \%$ showed immediate Raymond I or II occlusion, and at 6-month follow-up, the rate increased to $87.9 \%$, thus supporting the use of the PulseRider device. ${ }^{22}$ Notably, AguilarSalinas and colleagues systematically reviewed the use of PulseRider device in bifurcation aneurysms, across three studies conducted throughout Europe and the USA. A total of 63 aneurysms were treated and although it seems 'safe and probably effective' for treating intracranial bifurcation aneurysms, a bigger sample size is needed to support this statement. ${ }^{23}$ More recently, Srinivasan et $a l^{24}$ reported early postmarket results across 13 centres in the USA for the treatment of 54 aneurysms. Both clinical and radiographic outcomes were comparable with early studies with technical success in 52 cases (96.2\%), major complications in three cases and immediate Raymond I or II occlusion in $69.1 \%$. Follow-up angiography at 3 or 6 months was only available in 28 patients, and in these cases, observed Raymond I or II occlusion was $92.7 \%$. Further long-term outcomes with the use of PulseRider device and additional experiences in off-label indications are still needed.

Low-profile Visualised Intraluminal Support (LVIS) and LVIS Jr The LVIS and LVIS Jr stents are hybrid braided and closedcell nitinol stents approved for treating wide-neck aneurysms by the FDA on 30 May $2018 .{ }^{25}$ The LVIS is delivered through a larger microcatheter (0.021" inner diameter), while the LVIS Jr is delivered through a smaller microcatheter $\left(0.017^{\prime \prime}\right.$ inner diameter $){ }^{26}$ The use of a smaller microcatheter with LVIS Jr allows easier access to smaller vessels with a more tortuous path. In 2018, a multicentre retrospective analysis was conducted at seven medical centres ( six in the USA and one in Croatia) to investigate the technical and clinical outcome in LVIS Jr assisted coiling for the treatment of wide-neck aneurysms. The authors used the LVIS Jr in Y-stent configuration to treat
30 wide-neck bifurcation aneurysms (24 unruptured) in 30 patients. The use of LVIS Jr device resulted in immediate complete obliteration of aneurysm in 26 patients out of $30(89.6 \%)$. At a mean follow-up of 5.2 months, 23 patients out of $26(96 \%)$ had complete occlusion. This study supports the use of Y-stenting with the LVIS Jr device to assist in endovascular coiling of bifurcated, wide-neck cerebral aneurysms. ${ }^{27}$

Several other important studies evaluating the safety and effectiveness of the LVIS have since been published. A pivotal, prospective, multicentre trial for LVIS published its final results in 2019. The study enrolled 153 patients with wide-neck cerebral aneurysms from 21 US institutions. Complete occlusion was observed in $79.1 \%$ (110/139) after 12 month angiography, while $90 \%$ or greater occlusion was observed in $95 \%$ (132/139). Adverse effects (stroke or death) was observed in $5.2 \%(8 / 153){ }^{28}$ In a single-centre retrospective study comparing 229 patients treated with three different types of stents, the authors found that a higher degree of complete occlusion was observed for patients receiving LVIS and LVIS Jr devices $(49 / 60,81.7 \%)$, compared with those receiving the laser-cut open design stent and laser-cut closed design stent, during follow-up angiography at least 6 months after treatment; however, the authors do report that intraprocedural complications were higher for patients in the LVIS group $(7 / 69,10.1 \%) .{ }^{29}$ A multicentre retrospective study with 659 patients published in 2019 shows a statistically significant difference $(p=0.004)$ in complete occlusion for $84 \%$ of patients receiving LVIS stent $(251 / 299)$ compared with $78 \%$ of those receiving Neuroform stent $(117 / 150)$ and $67 \%$ of those Enterprise stent (83/123). The complete occlusion was determined from follow-up angiography, occurring an average of 10.5 months after treatment. $^{30}$

\section{Neuroform Atlas Stent System}

Neuroform Atlas Stent System is the newest vascular reconstruction device, approved by the FDA on 16 May 2019 (Stryker Neurovascular). It is a nitinol self-expanding stent redesigned from the previous Neuroform stent system by incorporating a hybrid closed cell and open cell design aimed to assist wide-neck aneurysm endovascular coiling. It is one of the most commonly used vascular reconstruction device (VRD) for stent-assisted coiling techniques with its ease of use through a smaller microcatheter (0.017" inner diameter) delivery. The Atlas Investigational Device Exemption (IDE) Trial was conducted at eight US centres to investigate the usefulness of Neuroform Atlas Stent System. Data from 27 patients were available at 12-month follow-up and 92.6\% (25/27) achieved complete occlusion. One patient suffered from stroke but recovered fully. The authors supported the use of the Neuroform Atlas Stent System in the treatment of cerebral aneurysms. ${ }^{31}$

In a prospective study of 55 bifurcation aneurysms, Ciccio $e t a l^{32}$ employed a double-stent technique in $\mathrm{Y}$ and $\mathrm{X}$ configurations with the Neuroform Atlas stent. 
The majority of cerebral aneurysms achieved complete occlusion $(n=33 ; 60 \%)$, while the remaining ones had either incomplete occlusion $(n=14 ; 25.4 \%)$ or neck remnant $(\mathrm{n}=8 ; 14.5 \%)$. Digital subtraction angiography (DSA) between 1 year and 3 years (mean=16 months) showed that follow-up data were available for 38 aneurysms in which $87 \%(\mathrm{n}=33)$ were completely occluded, $5 \%(\mathrm{n}=2)$ were incompletely occluded and $8 \%(\mathrm{n}=3)$ had a neck remnant. The procedural complication rate was $12.7 \%$, which was considered high; therefore, the authors cautioned the use of double stent-assisted coiling. ${ }^{32}$

\section{Barrel VRD}

The Barrel VRD (Medtronic/Covidien, Irvine, CA, USA) is a novel, fully retrievable, self-expanding, laser cut, nitinol stent designed as an adjunctive treatment for endovascular coiling of wide-neck bifurcation aneurysms. ${ }^{33}$ The unique feature of the Barrel VRD is its bulged centre, which allows greater aneurysm neck coverage with a single implant, as opposed to a double stent implant. It is delivered through a 0.021 -inch inner diameter microcatheter. Although it has received CE approval for use in Europe, the Barrel VRD has not obtained FDA approval for US market use.

In a prospective, multicentre trial, Gory et $a l^{33}$ enrolled 20 patients with wide-neck bifurcation aneurysms, 19 of which were ultimately treated with Barrel VRD as an adjunct to coil embolisation. At 12-month angiographic follow-up, 63\% (12/19) of patients experienced complete occlusion, while $79 \%(15 / 19)$ with neck remnant or complete occlusion were considered successfully treated. The authors reported a $5.3 \%$ (1/19 patients) rate of neurological complication. In a later study, Kabbasch et $a l^{34}$ published a two-centre retrospective analysis of 21 patients with wide-neck bifurcation aneurysms undergoing Barrel VRD stent-assisted endovascular coiling. The authors report that $90 \%(19 / 21)$ of patients experienced immediate complete occlusion. Of the patients available for short-term and midterm follow-up, 95\% (19/20) experienced complete occlusion (median follow-up 282 days, range: 17-591 days). Two patients experienced in-stent thrombus formation and one patient experienced in-stent stenosis; however, these complications were medically resolved. These results support a satisfactory safety profile. ${ }^{34}$ Despite the initial experiences, the Barrel VRD has not gained wide adoption.

\section{Comaneci}

On 7 May 2019, FDA approved the use of Comaneci device as a Temporary Coil Embolization Assist Device (Rapid Medical, Israel) to assist with coiling wide-neck aneurysms. The Comaneci device comes in three different sizes: (1) Comaneci is $32 \mathrm{~mm}$ in net length and expands to $4.5 \mathrm{~mm}$ in diameter; (2) Comaneci Petit is $24 \mathrm{~mm}$ in net length and expands to $3.5 \mathrm{~mm}$; and (3) Comaneci 17 is $22 \mathrm{~mm}$ in net length and expands to $3.0 \mathrm{~mm} .{ }^{35}$ Sirakov et $a l^{36} 2018$ described their experience with Comaneci in treating ruptured wide-neck aneurysms. Complete occlusion was achieved in $86 \%(25 / 29)$ of the patients, and only one patient had possibly procedure-related complications, thus supporting the use of Comaneci in treating ruptured aneurysms. Additionally, Sirakov et al described the use of two Comaneci devices in a challenging case: a bifurcated, wide-necked and ruptured aneurysm located at the basilar artery. The use of two Comaneci devices allowed the endovascular coiling to be successfully deployed and stabilised inside the aneurysm. The patient had a full recovery and no neurological deficit. Based on the DSA at 3 and 12 months of follow-up, aneurysm recurrence was not observed, indicating that the aneurysm was obliterated, along with patent bilateral posterior cerebral arteries. This case report demonstrated the advantage and the potential of using multiple Comaneci devices to manage similar complex anatomical configuration. ${ }^{37}$ Experience with the Comaneci devices remains few and limited at this time.

\section{Cascade Non-0cclusive Remodeling Net}

Cascade (Perflow Medical, Netanya, Israel) is a novel, retrievable, neck-bridging device designed to assist in coil embolisation of cerebral aneurysms. Cascade, like other neck-bridging devices, may serve as an alternative to balloon-assisted techniques, with the added advantage of providing patency of the parent vessel during coil delivery, thus reducing risk of complications associated with ischaemia. Sirakov et al report an early 2019 clinical experience using Cascade with coil embolisation for treatment for 12 ruptured wide-neck aneurysms. Complete occlusion was observed in $75 \%(9 / 12)$ patients, and no patients received antiplatelet therapy. No technical or clinical complications were observed during treatment; however, the study did not report follow-up data. The Cascade is similar to Comaneci (see section dedicated to Comaneci); however, Cascade is compatible with a smaller 0.017 microcatheter better suited for more tortuous vessels. Cascade features denser net and deflected shape during expansion unlike Comaneci. Sirakov $e t a l^{12}$ report less coil entanglement and better compliance with parent vessel during expansion with Cascade compared with Comaneci. The authors acknowledge several limitations of their study, such as the small sample size and lack of long-term follow-up. The higher rate of complications for patients undergoing endovascular coiling for wide-neck aneurysms remains an important issue, and early data for the use of the novel non-occlusive Cascade device appear promising and warrant further safety and efficacy studies.

The pCONus is a laser-cut, self-expanding, nitinol stent with a distal crown and four petals that are deployed into the aneurysm sac. It is compatible with 0.021 -inch diameter microcatheters. This device is currently approved for use in Europe but not in the USA by the FDA. ${ }^{38} 39$ The distal portion of stent consists of six polyamide fibres that cross and provide additional support to the coil ball in the aneurysm. The proximal extra aneurysmal portion consists of segmental radiopaque markers made of platinum-iridium wire that is released into the parent 
vessel to aid accurate positioning of the stent. In a recent meta-analysis and systematic review of 203 cerebral aneurysms treated with pCONus devices, it was found that the technical success rate was $100 \%$, technical complication rate was $0 \%$, complete occlusion rate was $60 \%$, retreatment rate was $14 \%$, morbidity rate was $7 \%$ and mortality rate was $0 \%{ }^{40}$

The second-generation device, pCONus 2, has two additional petals and a distal crown with a central spur. The design allows the crown to articulate providing additional flexibility, especially for aneurysms with high angulation between parent vessel and aneurysm. Centrally, the pCONus 2 has greater metal coverage to decrease the risk of coil prolapse. An early clinical experience with pCONus 2 involving 12 patients in the anterior and posterior circulations has been published. In this retrospective analysis, the authors report $92 \%(11 / 12)$ aneurysms with a modified RRC I (complete occlusion) and 8\% $(1 / 12)$ aneurysm with a modified RRC II after immediate angiography posttreatment. In angiographic follow-up (mean $=4.6$ months, range $=3-6$ months , adequate aneurysm occlusion was observed in $83 \%(5 / 6)$ and aneurysm recanalisation in $17 \%(1 / 6)$. The use of pCONus 2 did not result in any haemorrhagic complications or death. ${ }^{39}$

The pCANvas is the third-generation device to its predecessors, pCONus 1 and pCONus 2, used to treat wide-neck intracranial aneurysms (Phenox, Bochum, Germany). This device is also only currently approved for use in Europe but not in the USA by the FDA. The pCANvas consists of a detachable, laser-cut, neck bridging stent shaft with a distal crown of petals covered in a biocompatible membrane that inhibits blood flow into the aneurysm and prevents coil displacement into parent artery. A novel feature of pCANvas is its four radioopaque markers on the distal crown allowing accurate deployment at the aneurysm neck. Lylyk et al ${ }^{13}$ in 2019 published the earliest clinical data on the use of pCANvas. In a retrospective analysis of prospectively collected data, the authors included 17 patients treated for intracranial aneurysms with the pCANvas alone. The device was deployed without intraoperative complications. At early follow-up (median=6.1 months, range=3-10 months), five aneurysms were completely occluded (RRC I) and 11 were completely filled (RRC III). Seven patients were retreated with endovascular coiling because the pCANvas device as a singular treatment failed to occlude the aneurysm. Fourteen patients were available for midterm follow-up (median=18.2 months, range=7-38 months): $57 \%(8 / 14)$ aneurysms were completely occluded (RRC I), 21\% (3/14) aneurysms were completely filled (RRC III) and 21\% (3/14) aneurysms had neck remnants (RRC II). The authors conclude the pCANvas appears safe, and they recommend that the device be used as an adjunctive device to coiling.

\section{eCLIPS}

The second-generation eCLIPS is a novel self-expanding, fully retrievable, nitinol, stent-like device with flow diverter properties and the successor to the original eCLIPS device first described in 2008. This device is only currently approved for use in Europe but not in the USA by the FDA. Unlike its predecessor, the secondgeneration eCLIPS is not balloon mounted and its noncircumferential design prevents jailing of branch or parent vessels. The device has a leaf segment that diverts blood flow away from the aneurysm and acts as a scaffold for neointimal hyperplasia to cover the aneurysm neck. An initial clinical experience with the second-generation eCLIPS was published in 2018, describing a multicentre analysis of 33 patients with bifurcation aneurysms, mostly at the basilar tip, receiving eCLIPS implantation. The device was successfully deployed in $76 \%$ (25/33) patients, and coils were added during device implantation in all but two patients. The authors attribute the unsuccessful deployments to the learning curve associated with the new device, as the device was successfully implanted in all patients included in the study following the first year of use. Regarding safety, the authors report two ischaemic complications and two asymptomatic thrombotic events. Eighty-one per cent $(17 / 21)$ of patients demonstrated complete occlusion or residual neck at angiographic follow-up (mean=8 months, range $=3-18$ months). Of these 21 patients, $42.9 \%$ of patients had an improvement in RRC grade at follow-up. ${ }^{41}$ The European eCLIPS Safety, Feasibility, and Efficacy study is an ongoing multicentre prospective study that should help determine the utility of eCLIPS for the treatment of cerebral bifurcation aneurysms (ClinicalTrials.gov).

\section{ADVANCES IN COIL PROPERTIES}

Following the invention of the original Guglielmi detachable bare platinum coils in 1990s, numerous coil property modifications have been made to optimise various components of the system from improved detachment mechanisms, increasing coil lengths, softer coils and coatings to increase the aneurysmal thrombotic effect. A variety of coil shapes are available from two-dimensional helix to 360 or three-dimensional (3D) configurations. ${ }^{5}$ Multiple manufactures now offer coil lines with varying degrees of stiffness, from frame building (eg, Target 3D (Stryker Neurovascular or Micrusframe (Cerenovus, Irvine, CA, USA)), filling with soft to supersoft and finishing with nanos (eg, Target Nano (Stryker Neurovascular), Axium EX (Medtronic Neurovascular), or Galaxy G3 Mini (Cerenovus). The addition of nano-type coils with the softest properties to date and increased conformability offer the advantages of treating more challenging, smaller aneurysms or finishing small residual spaces towards the end of coiling procedures. To address larger aneurysms, larger coil diameters combined with significantly increased coil lengths as long as $50-60 \mathrm{~cm}$ are now available (eg, Target XL (Stryker Neurovascular) and Penumbra Coil 400 (Penumbra, Alameda, California, USA)). 
Several coil lines offer coatings with polyglycolic/polylactic acid (PGLA) microfilament (eg, Axium MicroFX (Medtronic Neurovascular), Cerecyte coil (Micrus Endovascular) and Matrix detachable coil (Boston Scientific/ Target, Fremont, California, USA)). In 2015, the final results of the prospective and multicentre trial, Axium MicroFX for Endovascular Repair of IntraCranial Aneurysm Study(AMERICA), was published. The authors reported a technical success rate of $99 \%$ and delayed adverse event rate of $2 \%$. A percentage of 90.6 of aneurysms were graded with complete occluded (RRC I) or residual neck (RRC II) at follow-up (mean=158 days, range $1-445$ days)..$^{542} 43$

Alternative coating option is the platinum and hydrophilic acrylic copolymer found in the second-generation Hydrogel family of coils (MicroVention). ${ }^{44}$ In Europe, the German-French Randomized Endovascular Aneurysm Trial (GREAT) showed that in a group of 484 patients (226 patients treated with hydrogel and 230 patients treated with bare platinum), $19.9 \%$ of patients treated with hydrogel had unfavourable outcomes such as aneurysm recurrence, retreatment, mRS (modified Rankin Scale) of 3-5 and death as compared with $28.7 \%$ of patients treated with bare platinum. The authors recommended the use of second-generation hydrogel coils. ${ }^{6}$ In the USA, a similar trial was conducted, called the New Generation Hydrogel Endovascular Aneurysm Treatment (HEAT) Trial, which examined aneurysm recurrence within 18 months post-treatment between patients who were treated with the second-generation HydroCoil Embolic System (HES) and patients treated with the traditional platinum coils. In a total of 600 patients, 297 were treated with HES (HydroCoil Embolic System) and 303 were treated with platinum coils. The HES group had a significantly lower aneurysm recurrence rate of $4.4 \%$ than the platinum group of $15.4 \%$, suggesting the use of the second-generation hydrogel coils over platinum coils in the treatment of cerebral aneurysms. ${ }^{44}$

\section{OTHER COILING TECHNIQUE INNOVATIONS \\ 3D printed vascular models}

3D printing of artificial vascular models for pretreatment simulation holds promise for guiding the treatment of intracranial aneurysms, particularly those that are more challenging to treat. These silicone vascular replicas can be made for less than US\$2 and in 24 hours using a desktop 3D printer costing approximately $\$ 1300$. Data from CT, magnetic resonance angiography or rotational angiography can be used to generate a printable vascular model tailored to a patient's unique anatomy, then further processed with the addition of a liquid silicon coat, smoothing out of the artificial vessels, and attachment to peristaltic pump to allow simulation with endovascular devices. ${ }^{45}$ In a case report involving two patients, Kaneko et $a l^{46}$ designed and printed patientspecific hollow vascular models to determine the optimal endovascular treatment for more challenging to treat aneurysms. The first case was a wide-neck A3 aneurysm, pretreatment simulation led the authors to use the Neuroform ATLAS stent over the LVIS Jr stent based on degree of stent herniation into the aneurysmal sac. The second case was a wide-neck basilar-superior cerebellar artery aneurysm where Neuroform ATLAS was chosen over LVIS Jr based on superior coil embolidation stability using Neuroform Atlas during pretreatment simulation. In this small number of patients, simulation accurately predicted the outcome of the procedure and aided in deciding which stent would likely be more effective for each specific patient based on degree of side branch protection, coil embolisation stability and degree of stent expansion. The authors note a few limitations in their study, namely the challenge in replicating vascular elasticity in their printed silicon vascular models, which are more fixed and inelastic compared with human vessels. Nonetheless, these results are promising and additional studies with a greater sample size appear to be warranted to assess the utility of using personalised 3D-printed vascular models for preprocedural simulation of endovascular coiling.

\section{CONCLUSIONS}

Endovascular coiling techniques have continued to evolve since the initial invention of Guglielmi detachable coils in the 1990s. Advancements in vascular reconstruction intracranial stents now provide low profile alternatives with delivery via small 0.017 -inch microcatheters. Improvements in balloon microcatheters now provide super compliant comformable balloons designed for treatment of wide-neck aneurysms with dual lumen capabilities and improved navigation via 0.014-inch microwires. More recently, novel stent-like temporary bridging devices and alternative stents with semiflow diverting properties also aim to broaden the efficacy of coiling techniques. It remains to be seen how use of coiling and adjunctive devices will change with greater adoption of the flow modulation braided devices such as WEB (Woven EndoBridge device; MicroVention). Finally, use of 3D-printed vascular simulation flow models are gaining popularity for preprocedure planning to assist with appropriate device selection and sizing. The endovascular field continues to evolve and advance with innovative devices further raising the bar for the safety and efficacy of cerebral aneurysm treatments.

\section{Twitter Jessica K Campos @drjessicacampos}

Contributors JKC conceived the project. BL and ASW wrote the initial draft of the manuscript. JKC and L-ML revised the manuscript.

Funding The authors have not declared a specific grant for this research from any funding agency in the public, commercial or not-for-profit sectors.

Competing interests L-ML is a proctor for Stryker Neurovascular, MicroVentionTerumo and Medtronic Neurovascular.

Patient consent for publication Not required.

Provenance and peer review Commissioned; externally peer reviewed.

Open access This is an open access article distributed in accordance with the Creative Commons Attribution Non Commercial (CC BY-NC 4.0) license, which 
permits others to distribute, remix, adapt, build upon this work non-commercially, and license their derivative works on different terms, provided the original work is properly cited, appropriate credit is given, any changes made indicated, and the use is non-commercial. See: http://creativecommons.org/licenses/by-nc/4.0/.

\section{ORCID iDs}

Jessica K Campos http://orcid.org/0000-0003-1075-0764

Li-Mei Lin http://orcid.org/0000-0002-6963-9799

\section{REFERENCES}

1 Molyneux A, Kerr R, Stratton I, et al. International subarachnoid aneurysm trial (ISAT) of neurosurgical clipping versus endovascular coiling in 2143 patients with ruptured intracranial aneurysms: a randomized trial. J Stroke Cerebrovasc Dis 2002;11:304-14.

2 Spetzler RF, McDougall CG, Zabramski JM, et al. The Barrow ruptured aneurysm trial: 6-year results. J Neurosurg 2015;123:609-17.

3 Jiang B, Paff M, Colby GP, et al. Cerebral aneurysm treatment: modern neurovascular techniques. Stroke Vasc Neurol 2016;1:e000027:93-100.

4 Raymond J, Guilbert F, Weill A, et al. Long-term angiographic recurrences after selective endovascular treatment of aneurysms with detachable coils. Stroke 2003;34:1398-403.

5 Zhu $\mathrm{Y}$, Zhang $\mathrm{H}$, Zhang $\mathrm{Y}$, et al. Endovascular metal devices for the treatment of cerebrovascular diseases. Adv Mater 2019;31:1805452

6 Taschner CA, Chapot R, Costalat V, et al. Second-generation hydrogel coils for the endovascular treatment of intracranial aneurysms: a randomized controlled trial. Stroke 2018;49:667-74.

7 Hendricks BK, Yoon JS, Yaeger K, et al. Wide-neck aneurysms: systematic review of the neurosurgical literature with a focus on definition and clinical implications. J Neurosurg 2019;14:1-7.

8 Taqi MA, Quadri SA, Puri AS, et al. A prospective multicenter trial of the transform occlusion balloon catheter: trial design and results. Interv Neurol 2018;7:53-64.

9 Akpek S, Arat A, Morsi H, et al. Self-expandable stent-assisted coiling of wide-necked intracranial aneurysms: a single-center experience. AJNR Am J Neuroradiol 2005;26:1223-31.

10 Colby GP, Paul AR, Radvany MG, et al. A single center comparison of coiling versus stent assisted coiling in 90 consecutive paraophthalmic region aneurysms. J Neurointerv Surg 2012;4:116-20.

11 Piotin M, Blanc R, Spelle L, et al. Stent-assisted coiling of intracranial aneurysms: clinical and angiographic results in 216 consecutive aneurysms. Stroke 2010;41:110-5.

12 Sirakov S, Sirakov A, Minkin K, et al. Early clinical experience with cascade: a novel temporary neck bridging device for embolization of intracranial aneurysms. J Neurointerv Surg 2020;12:303-7.

13 Lylyk P, Chudyk J, Bleise C, et al. Treatment of Wide-Necked Bifurcation Aneurysms : Initial Results with the pCANvas Neck Bridging Device. Clin Neuroradiol 2019;29:467-77

14 Moret J, Cognard C, Weill A, et al. The "Remodelling Technique" in the Treatment of Wide Neck Intracranial Aneurysms. Angiographic Results and Clinical Follow-up in 56 Cases. Interv Neuroradiol 1997;3:21-35.

15 Piotin M, Blanc R. Balloons and stents in the endovascular treatment of cerebral aneurysms: vascular anatomy remodeled. Front Neurol 2014;5:41.

16 Alaraj A, Wallace A, Dashti R, et al. Balloons in endovascular neurosurgery: history and current applications. Neurosurgery 2014;74:S163-90.

17 Quadri SA, Ramakrishnan V, Hariri O, et al. Early experience with the TransForm occlusion balloon catheter: a single-center study. Interv Neurol 2015;3:174-83.

18 Pierot L, Spelle L, Leclerc X, et al. Endovascular treatment of unruptured intracranial aneurysms: comparison of safety of remodeling technique and standard treatment with coils. Radiology 2009;251:846-55.

19 Pierot L, Cognard C, Anxionnat R, et al. Remodeling technique for endovascular treatment of ruptured intracranial aneurysms had a higher rate of adequate postoperative occlusion than did conventional coil embolization with comparable safety. Radiology 2011;258:546-53.

20 Shapiro M, Babb J, Becske T, et al. Safety and efficacy of adjunctive balloon remodeling during endovascular treatment of intracranial aneurysms: a literature review. AJNR Am J Neuroradiol 2008;29:1777-81.
21 PulseRider Aneurysm Neck Reconstruction Device. Department of Health \& Human Services, 2017. Available: https://www.accessdata. fda.gov/cdrh_docs/pdf16/H160002A.pdf [Accessed Nov 2019].

22 Spiotta AM, Derdeyn CP, Tateshima S, et al. Results of the answer trial using the PulseRider for the treatment of broad-necked, bifurcation aneurysms. Neurosurgery 2017;81:56-65.

23 Aguilar-Salinas P, Brasiliense LBC, Walter CM, et al. Current status of the PulseRider in the treatment of bifurcation aneurysms: a systematic review. World Neurosurg 2018;115:288-94.

24 Srinivasan VM, Srivatsan A, Spiotta AM, et al. Early postmarket results with PulseRider for treatment of wide-necked intracranial aneurysms: a multicenter experience. J Neurosurg 2019:1-10.

25 Low-Profile Visualized Intraluminal Support (LVIS) and LVIS Jr. U.S. Food \& Drug Administration, 2018. Available: https://www. accessdata.fda.gov/cdrh_docs/pdf17/P170013A.pdf [Accessed Nov 2019].

26 Summary of safety and effectiveness data (SSED), 2018. Available: https://www.accessdata.fda.gov/cdrh_docs/pdf17/P170013B.pdf [Accessed Nov 2019].

27 Samaniego EA, Mendez AA, Nguyen TN, et al. LVIS Jr device for ystent-assisted coil embolization of wide-neck intracranial aneurysms: a multicenter experience. Interv Neurol 2018;7:271-83.

28 Fiorella D, Boulos A, Turk AS, et al. The safety and effectiveness of the LVIS stent system for the treatment of wide-necked cerebral aneurysms: final results of the pivotal us LVIS trial. J Neurointerv Surg 2019;11:357-61.

29 Wang J, Vargas J, Spiotta A, et al. Stent-assisted coiling of cerebral aneurysms: a single-center clinical and angiographic analysis. $J$ Neurointerv Surg 2018;10:687-92.

30 Mokin M, Primiani CT, Ren Z, et al. Stent-assisted coiling of cerebral aneurysms: multi-center analysis of radiographic and clinical outcomes in 659 patients. J Neurointerv Surg 2020;12:289-97.

31 Jankowitz BT, Hanel R, Jadhav AP, et al. Neuroform atlas stent system for the treatment of intracranial aneurysm: primary results of the atlas humanitarian device exemption cohort. J Neurointerv Surg 2019;11:801-6.

32 Ciccio G, Robert T, Smajda S, et al. Double stent assisted coiling of intracranial bifurcation aneurysms in $Y$ and $X$ configurations with the Neuroform atlas stent: immediate and mid term angiographic and clinical follow-up. J Neurointerv Surg 2019;11:1239-42.

33 Gory B, Blanc R, Turjman F, et al. The barrel vascular reconstruction device for endovascular coiling of wide-necked intracranial aneurysms: a multicenter, prospective, post-marketing study. $J$ Neurointerv Surg 2018;10:969-74.

34 Kabbasch C, Mpotsaris A, Maus V, et al. The Barrel Vascular Reconstruction Device : A Retrospective, Observational Multicentric Study. Clin Neuroradiol 2019;29:295-301.

35 RapidMedical. Comaneci adjustable remodeling mesh. Available: https://www.rapid-medical.com/comaneci [Accessed Nov 2019]

36 Sirakov S, Sirakov A, Hristov $\mathrm{H}$, et al. Early experience with a temporary bridging device (Comaneci) in the endovascular treatment of ruptured wide neck aneurysms. J Neurointerv Surg 2018;10:978-82.

37 Sirakov S, Sirakov A, Lylyk I, et al. Basilar artery bifurcation aneurysm: a ruptured wide-necked basilar bifurcation aneurysm, treated by dual Comaeci-assisted coil occlusion. The aneurysm casebook 2018:1-7

38 Labeyrie PE, Gory B, Aguilar-Perez M, et al. The pCONus device for treatment of complex wide-neck anterior communicating artery aneurysms. World Neurosurg 2017;101:498-505.

39 Lylyk P, Chudyk J, Bleise C, et al. The pCONus2 neck-bridging device: early clinical experience and immediate angiographic results. World Neurosurg 2018;110:e766-75.

40 Sorenson TJ, lacobucci M, Murad MH, et al. The pCONUS bifurcation aneurysm implants for endovascular treatment of adults with intracranial aneurysms: a systematic review and meta-analysis. Surg Neurol Int 2019;10:24.

41 Chiu AH, De Vries J, O'Kelly CJ, et al. The second-generation eCLIPs endovascular clip system: initial experience. J Neurosurg 2018;128:482-9.

42 Fargen KM, Blackburn S, Deshaies EM, et al. Final results of the multicenter, prospective Axium MicroFX for endovascular repair of intracranial aneurysm study (America). J Neurointerv Surg 2015;7:40-3.

43 Waldau B, Fargen KM, Mack WJ, et al. Axium MicroFX coil for the completing endovascular aneurysm surgery study (access). A prospective evaluation of the safety and durability of Axium MicroFX PGLa coils. Interv Neuroradiol 2012;18:200-7.

44 Abi-Aad KR, Aoun RJN, Rahme RJ, et al. New generation hydrogel endovascular aneurysm treatment trial (HEAT): a study protocol 
for a multicenter randomized controlled trial. Neuroradiology 2018;60:1075-84.

45 Kaneko N, Mashiko T, Ohnishi T, et al. Manufacture of patientspecific vascular replicas for endovascular simulation using fast, low-cost method. Sci Rep 2016;6:39168.
46 Kaneko N, Minhas A, Tateshima S, et al. Pre-procedural simulation for precision stent-assisted coiling of cerebral aneurysm. Interv Neuroradiol 2019;25:419-22. 